\title{
A practitioners' view on the application of water and flood directives in Italy
}

\author{
Marta Martinengo, Antonio Ziantoni, Fabio Lazzeri, Giorgio Rosatti and Riccardo Rigon
}

\begin{abstract}
The commonly called Water Framework Directive ${ }^{1}$ (WFD) and Flood Directive ${ }^{2}$ (FD) represent pivotal points for European water policies. They do not need any further introduction here since there are other contributions to this book that present them in detail. In this chapter, we briefly describe how they affect people working in Italy in water resources management, exploitation and protection of and from water bodies. In this contribution, we try to present the work needed to fulfil the directives generally, who did the work and with what responsibilities in past implementation cycles, and what was actually done in implementation cycle for both directives up to 2016. The result is a picture of the Italian water management system; a system not only defined by laws and norms, but also by habits and the way Institutions have developed during recent history through their interplay with growing technical knowledge, the implementation of policies, and the evolution of Italian society. This chapter is divided as follows: section 1 reports what has to be done to accomplish the directives generally; section 2 summarizes who performed the actions connected to the directives in past implementation cycles; section 3 and 4 report and discuss the Italy's application of the directive; section 5 covers the role of science in the implementation of the directives; and, finally, section 6 contains some considerations on the main critical aspects and on the challenges the future application of the directives (20212027) is going to face.
\end{abstract}

\section{1 - Introduction (What has to be done)}

Compliance with WFD and FD is a huge task that affects a considerable portion of the economy and is subject to the evolving understanding of water-related processes by

\footnotetext{
${ }^{1}$ Directive 2000/60/EC of the European Parliament and of the Council of 23 October 2000 establishing a framework for Community action in the field of water policy. Available at https://eurlex.europa.eu/resource.html?uri=cellar:5c835afb-2ec6-4577-bdf8-756d3d694eeb.0004.02/DOC 1\&format=PDF

${ }^{2}$ Directive 2007/60/EC of the European Parliament and of the Council of 23 October 2007 on the assessment and management of flood risks. Available at https://eur-lex.europa.eu/legal-content/EN/TXT/PDF/?uri $=$ CELEX:32007L0060\&from $=$ EN
} 
Earth Sciences and Engineering. As such, it requires integrated, interdisciplinary, and holistic approaches (Voulvoulis 2017) as well as reasoned debate between many social actors. Implementing the Directives affects everyone who works in the water management sector, from practitioners to government officials and given their comprehensive objectives, they cannot be accomplished once and for all: an iterative process is required, one based on the definition of practical measures and control of the results (Sabel and Zeitlin 2012). For this reason, both Directives are based on a six-year cycle of planning approach. The first management cycle of the WFD ran from 2009 - 2015 and the second from 2015 - 2021. In harmony with the WFD, the FD first management cycle ran from 2015 - 2021. The timetable of the main key stages of the WFD and FD implementation, described below, are shown in Figure 1 (European Commission 2014) and the related layers and deliverables are presented in Figure 2.

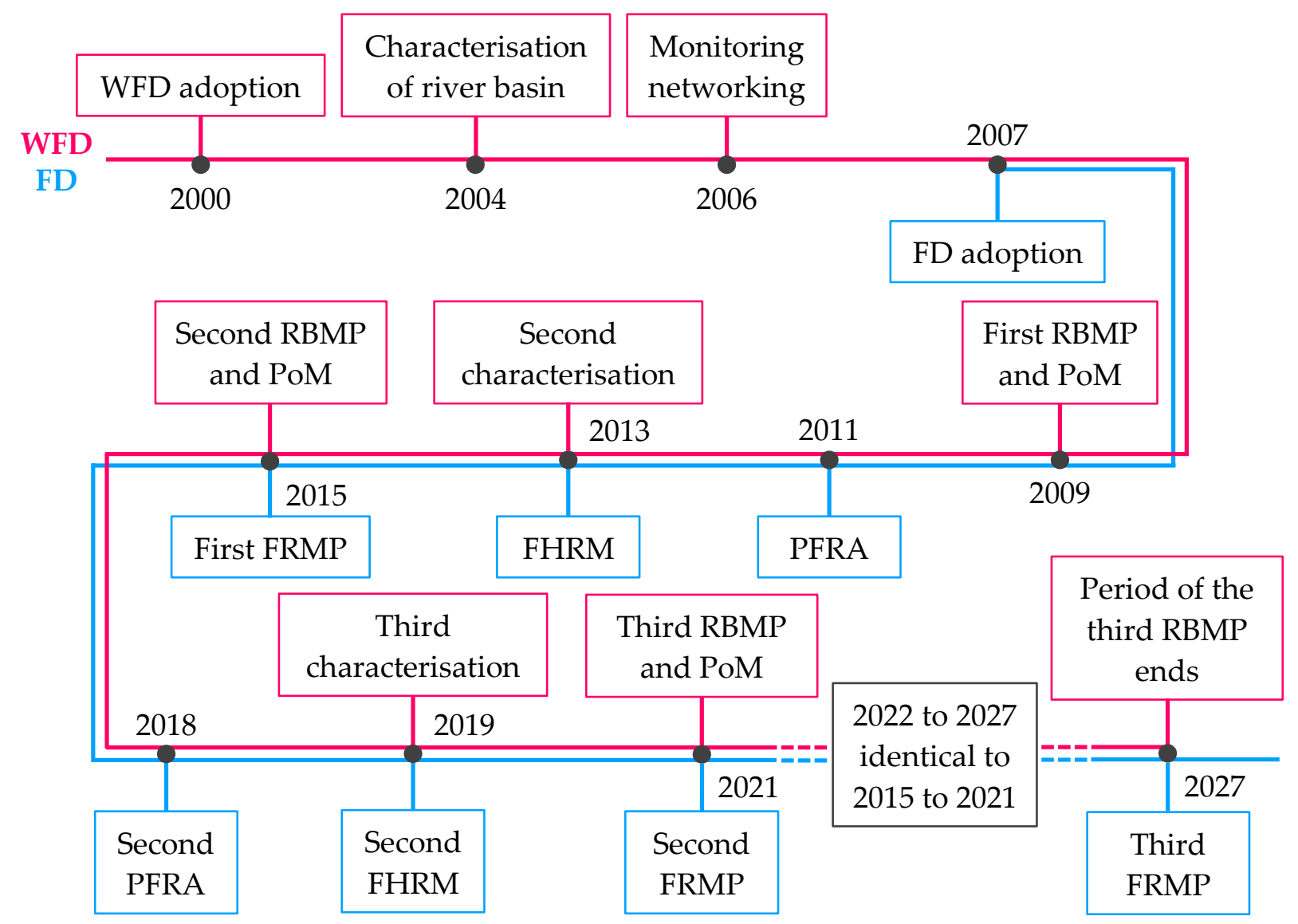

Figure 1 - The timetable of the main key stages of the WFD and FD implementation. The meaning of acronyms is described in the list of acronyms at the end of the chapter.

According to Art. 1 of the WFD, the purpose of the directive is the protection of all waters preventing further deterioration and enhancing the waters status, promoting sustainable use of water, reducing discharges, emissions, priority substance losses and pollution and mitigating the floods and droughts effects. Overall, the key objective of the 
WFD is to maintain or achieve good water status for all water bodies (European Commission 2003a).

To achieve this objective, the key actions to be taken are (i) to characterise the river basins, identifying pressures and impacts of human activity on water body status and performing an economic analysis of water use; (ii) to develop monitoring programmes; (iii) to establish River Basin Management Plans (RBMPs) and Programmes of Measures (PoMs) defining the environmental objectives to manage pressures and impacts and to achieve good status (European Commission 2014) (Figure 1).

The characterisation of the river basins requires many types of data and inventories that allow to describe the drainage basin, the pressures and the impacts and to perform an economic analysis. The collection of data and inventories is the first step necessary to implement the WFD and, for this reason, is shown as "basic layer" element (red rectangle) in Figure 2. Measuring the state of a water system is very complicated. It usually requires identifying quality elements and, for each element, a quantitative indicator of quality, whose value can be used as a measure of performances (Voulvoulis 2017). A classification must be established and have to be composed of five classes, for surface waters, and two classes, for groundwaters (European Commission 2003b). The quality elements cover a wide range of areas and can be classified into biological, hydromorphological and physicochemical (European Commission 2003a). Examples of these are the permitted concentration of a certain substance in drinking water, the abundance of certain biota in a lake, the amount of pesticide in groundwater, the geomorphology of a stream. The quality indicators are

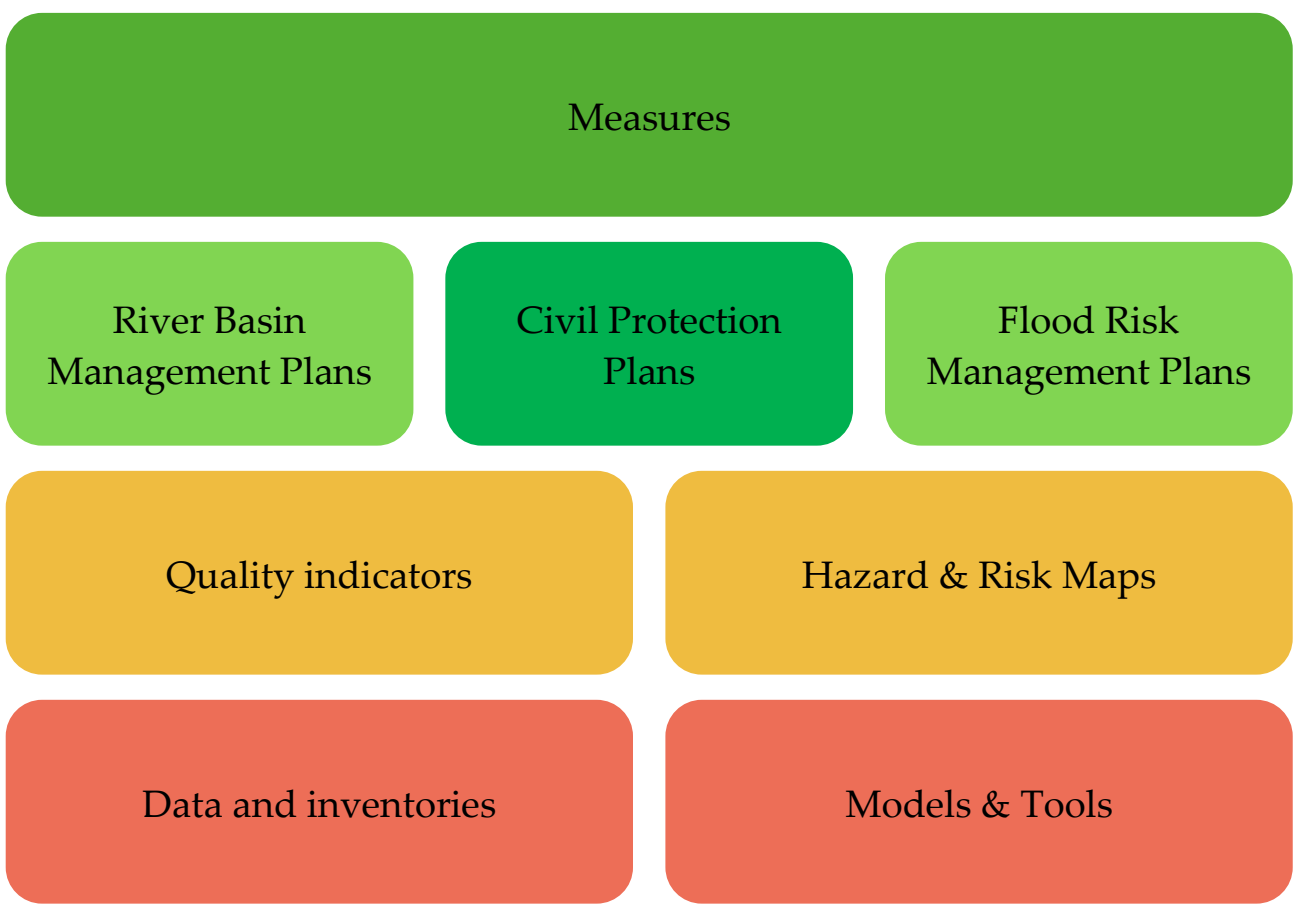

Figure 2 - Layers and deliverables related to the accomplishment of the WFD and FD. The red rectangles contain the element that constitute the "basic layer" for the directives' implementation. The intermediate and final deliverables of the directives are respectively reported in the yellow and green rectangles. 
intermediate tools in directive accomplishment and are shown in Figure 2 as intermediate deliverables (yellow rectangle).

According to Art. 8 of the WFD, the quality elements, once set, must be monitored "to establish a coherent and comprehensive overview of water status within each River Basin District" (European Commission 2003b) and, for this reason, a monitoring programme is required.

Moreover, to achieve the environmental objectives (Art. 4 of the WFD), a programme of measures (PoMs), based on the characterisation of the river basin and the results of the monitoring programme, must be established and implemented. Measures are shown in Figure 2 as one of the final deliverables (green rectangle) of the directive.

All the previously described information (i.e. characterisation, monitoring, objectives and measures to maintain or improve water status) should be included in the River Basin Management Plan (RBMP) that must be produced for each river basin district (European Commission 2003c). In Figure 2, RBMPs are shown in green since they represent a final deliverable of the directive.

The core goal of the FD differs from that of the WFD since it relates to the reduction and management of flood risk to human health, cultural heritage, environment and economic activities. Complying with the FD comprises three steps (Tsakiris et al. 2009): (i) preliminary flood risk assessment (PFRA); (ii) flood hazard and risk maps (FHRM); and (iii) Flood Risk Management Plan (FRMP) (Figure 1).

Once the areas with potential significant flood risk are identified, the flood hazard and risk maps should be developed for these areas. This means choosing a sequence of available models and tools to estimate the flood hazard and risk. In Figure 2, the red "Models and Tools" box is to indicate how they constitute an internal layer of deliverables in fulfilling the directive, almost as basic as data.

Furthermore, to develop the maps, FD is prescriptive in terms of flood return period for the hazard map (Art. 6(3)) and of vulnerable and exposed elements for the risk map (Art. 6(5)). The maps themselves are an intermediate deliverable of the process, represented in yellow in Figure 2.

The FRMP, shown in green in Figure 2, is drafted on the basis of the flood hazard and risk maps. It should establish the flood risk management objectives and related measures, and all aspects of flood risk management should be addressed, focusing on (i) prevention; (ii) protection; and (iii) preparedness (Art. 7(3)).

One of the main topics, common to both the WFD and the FD, is information dissemination and public consultation. Indeed, according to Art. 14 of the WFD and to Art. 9 and 10 of the FD, Member States should encourage the "active involvement of interested 
parties in the production, review and updating" of the plans. Institutions need to interact with communities to understand needs and get feedback and suggestions, related to the ongoing process. Deploying shared procedures, which grow into accepted solutions during the process, is by default the best case of all and this can be possible by making intermediate material and data available to the public.

To sum up, the directives require three types of deliverable. Data, inventories and models constitute the first level, quite hidden to the general public, but available to technicians (the red boxes in Figure 2). Based on these, indicators and maps of hazards and risks are produced as a second level (yellow boxes in Figure 2). RBMPs and FRMPs are the third level (the green boxes in Figure 2). To these deliverables, we also added Measures in Figure 2. These are contained in the management plans, but they are shown separately here because they involve activities from other actors, as clarified below. For completeness, in Figure 2 Civil Protection Plans have also been added; they are related to preparedness even if they are not the same type of product required by the FD.

\section{2 - Who (is who in Italy's water resources governance)}

In section 1, we briefly presented the technical processes behind the application of the WFD and FD. Here we summarize who manages them in Italy.

Besides the layers and deliverables already presented in Figure 2, the key actors and stakeholders involved in the implementation and accomplishment of the directives and their interactions, described below, are shown in Figure 3.

To apply the WFD, the Code on the Environment (Codice dell'ambiente - D. Lgs. 152/2006 ${ }^{3}$ ) subdivided the country into eight River Basin Districts (RBDs): Eastern Alps, Padan, North Apennines, Serchio, Central Apennines, South Apennines, Sardinia and Sicily (Figure 4). Since first establishing the Districts, there has been some reform to improve the system. With L. 221/20154, the territorial subdivision was modified, incorporating the Serchio RBD into the North Apennine RBD. With D.M. 294/20165, the Italian Government identified several Competent Authorities to implement the WFD at national, river catchment and regional levels (European Commission 2019b). Specifically, the Ministry of Environment (Ministero dell'Ambiente e della Tutela del Territorio e del Mare - MATTM)

\footnotetext{
${ }^{3}$ Legislative Decree 3 April 2006, n. 152 - Norme in materia ambientale.

${ }^{4}$ Law 28 December 2015, n. 221 - Disposizioni in materia ambientale per promuovere misure di green economy e per il contenimento dell'uso eccessivo di risorse naturali.

${ }^{5}$ Ministerial Decree 25 October 2016, n. 294 - Disciplina dell'attribuzione e del trasferimento alle Autorità di bacino distrettuali del personale e delle risorse strumentali, ivi comprese le sedi, e finanziarie delle Autorità di bacino, di cui alla legge 18 maggio 1989, n. 183.
} 
and the National Institute for Environmental Protection and Research (Istituto Superiore per la Protezione e la Ricerca Ambientale - ISPRA) are designated at the national level, the RDBs at the river basin level, and the Regions and Autonomous Province at the regional level.

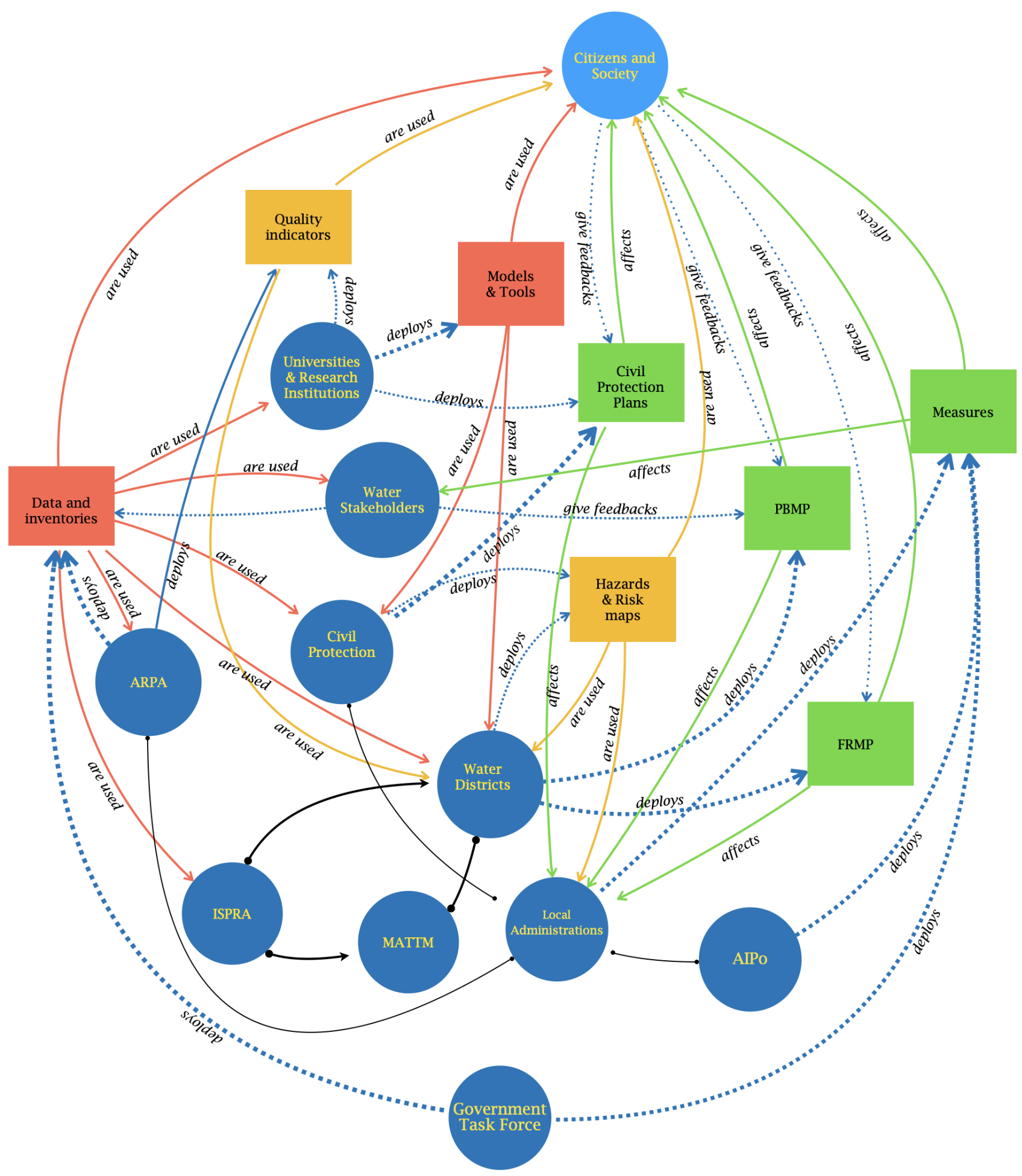

Figure 3 - WFD and FD in Italy: base level (red rectangles), intermediate (yellow rectangles) and final (green rectangles) deliverables, actors (blue circles), stakeholders (light blue circles) and their interactions. The meaning of acronyms is described in the list of acronyms at the end of the chapter 


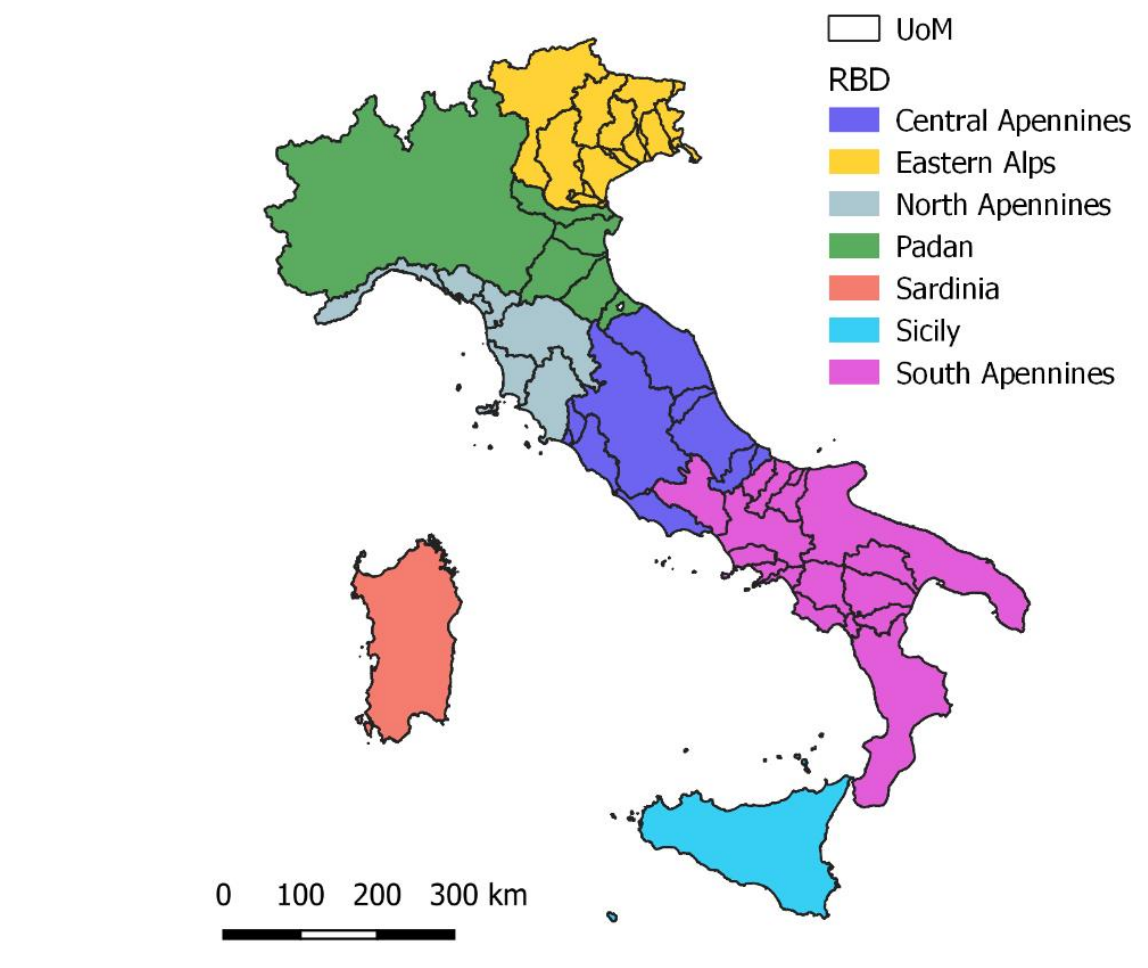

Figure 4 - Italy's River Basin Districts (RBDs - post L. 221/2015) and Units of Management (UoMs)

However, according to D. Lgs. 219/20106, the RBD Authorities have a coordination role for the implementation of the WFD within their districts. These institutions are shown as actors (blue circles) in Figure 3.

Furthermore, in accordance with Art. 3 of the FD, Italy has designed 47 Units of Management (UoMs) to accomplish the Directive (Figure 4). As described in European Commission 2019c, "the FRMPs are coordinated and prepared at RBD level and detailed at UoM scale by the Prime Competent Authorities (River Basin Authorities and Regional Authorities)".

According to D. Lgs. 152/2006 and D. Lgs. 49/20107, MATTM is in charge of the eight Italian basin districts, playing the role of director and harmonizer, while ISPRA supports MATTM with guidance on how the management plans should be written and deployed. In Figure 3, these Institutions are connected with a black line to indicate that they represent the State. Local administrations are shown separately because they have a different role in the process.

\footnotetext{
${ }^{6}$ Legislative Decree 10 December 2010, n. 219 - Attuazione della direttiva 2008/105/CE relativa a standard di qualità ambientale nel settore della politica delle acque, recante modifica e successiva abrogazione delle direttive 82/176/CEE, 83/513/CEE, 84/156/CEE, 84/491/CEE, 86/280/CEE, nonché modifica della direttiva 2000/60/CE e recepimento della direttiva 2009/90/CE che stabilisce, conformemente alla direttiva 2000/60/CE, specifiche tecniche per l'analisi chimica e il monitoraggio dello stato delle acque.

${ }^{7}$ Legislative Decree 23 February 2010, n. 49 - Attuazione della direttiva 2007/60/CE relativa alla valutazione e alla gestione dei rischi di alluvioni.
} 
Regional governments possess the capital to operate (provided by the State through various forms of financial support) and the duty to plan regional and local development (both urban and non-urban). Exceptions in the proposed governance chain are the Autonomous Regions and Provinces that have some specific prerogatives and, therefore, bypass part of the process, having all the competences themselves (Coen 2006). For instance, the Adige river basin falls in part in the provinces of Trento and Bolzano; these Autonomous Provinces exert their constitutional rights and produce indicators and hazard and risk maps for their territories on their own. Another exception in governance with respect to the rest of the country is given by Padan RBD. The Padan is the largest river basin and extends across North-West and North-Central Italy (Figure 3). In 2003, to harmonize the policies of the various regions that fall within the District (mainly Piemonte, Lombardia, EmiliaRomagna and Veneto), the Italian legislature instituted the Interregional Agency for the Po River (Agenzia Interregionale per il fiume Po, AIPo), a public body that provides engineering and environmental services related to flood risk mitigation. In Figure 3, AIPo is shown connected with the Local Authorities that it represents.

There are at least two other actors in the process who have not been mentioned yet, though they are shown in Figure 3: the Civil Protection Department (DPC) and the Regional/Provincial Environmental Protection Agency (Agenzia Regionale/Provinciale per la Protezione dell'Ambiente - ARPA/APPA). In Italy, hazards management cross not only the competence of Districts and Regions, but also the competence of the DPC. Indeed, according to Art. 7 of the D. Lgs. 49/2010, the preparation and implementation of the national, state and regional warning systems for hydraulic risk for civil protection purposes must be carried out by the Regions in coordination with the DPC. This highlights the dichotomy between the planning bodies (the RBDs) and the executing bodies (Regions, Autonomous Province and DPC) in flood risk management, a dichotomy that becomes evident in the civil protection plans. To support the DPC, the D.P.C.M. 38/2013 ${ }^{8}$ designated a group of Institutions, among which university departments and research centres, as Centres of Competence (CC) with the initial scope of supporting with scientific expertise the DPC in its duties. In practice, most of these Centres were never financed or utilized. In Figure 3, they mostly fall into the "Universities and Research Institutions" group, except AIPo, which is shown separately, even though it is formally declared a CC.

The current situation is even more interwoven than what is apparent. As mentioned previously, producing a map requires some type of modelling and usually many data. No practitioner can estimate floods without a considerable amount of meteorological,

\footnotetext{
${ }^{8}$ Decree of The President of The Council of Ministers 14 September 2012, n. 38 - Definizione dei principi per l'individuazione ed il funzionamento dei Centri di Competenza.
} 
hydrological and geological information. Any WFD indicator is the synthesis (a model) of many other data. Each model requires datasets for validation and verification. Data measurement, collection, storage and supply are key functions of the governance chain. Decision making can be centralized or regionalized, but data need to be collected locally. During the last decades, Italy has made a transition from national services providing data, as was the case of the Istituto Idrografico e Mareografico, to regionalized data providers, specifically the ARPAs (or equivalent services for the autonomous regions and provinces) (ISPRA, Inquadramento storico del monitoraggio idro-meteografico e delle relative competenze). With the D.L. 132/20169, the ARPAs together with ISPRA now constitute the National System for Environmental Protection (Sistema nazionale per la protezione dell'Ambiente, SNPA). The ARPAs, therefore, represent another actor in Figure 3 and are connected by a black line to the Local Administration of which they are part. From a practical point of view, by means of the ARPAs, the Regions give the raw material with which any analysis is produced. The ARPAs manage networks of hydro-meteorological stations and the routine water quality measurement and other environmental campaigns.

As is the case in many parts of the World, in Italy models are usually produced by Universities and Research Institutions, as shown in Figure 3, but we will talk about this in detail in the next section. Before, we have to make an annotation about the so-called "Strutture di Missione" (which can be translated as Institutional Task Force). Under previous Italian governments, these were instituted under the direct dependence of the Prime Minister to accomplish specific environmental tasks. An interesting case is that of "Italia Sicura" (Safe Italy). It was established in 2014 as a task force to mitigate hydrogeological risks. It also created a series of databases containing environmental data and released the data as open source. It's evident that the Italian government realized that the entire water management sector needed a boost, but it provided a further infrastructure in an already complicated institutional set-up. The subsequent government closed Italia Sicura but, at the same time, approved "ProteggItalia" (ProtectItaly, D.P.C.M. 20 February, $2019^{10}$ ) on the same lines as "Italia Sicura" and added two interesting keywords, "Simplification" and "Governance and Organization", about which we shall return in the discussion section.

\footnotetext{
${ }^{9}$ Law Decree 28 June 2016 - n. 132, Istituzione del Sistema nazionale a rete per la protezione dell'ambiente e disciplina dell'Istituto superiore per la protezione e la ricerca ambientale.

${ }^{10}$ Decree of The President of The Council of Ministers 20 February 2019 - Approvazione del Piano nazionale per la mitigazione del rischio idrogeologico, il ripristino e la tutela della risorsa ambientale.
} 
It should be clear at this point that the already complex system represented Figure 3 is even more articulated. Many of the circles are in fact containers of various subjects. Let us consider, for example, the water stakeholders represented in Figure 5: while some of these stakeholders are explicitly shown in Figure 3, many of them are not, and they are not even all the stakeholders. In Figure 5, the stakeholders have been subdivided into managers of the resource (in circles), managers of water services (in square), managers of both (in pentagons), and providers of technical advice (in diamonds). Colours are blue for public institutions, red for interest groups or lobbies. Bordered icons are those not included explicitly in Figure 3: they fall mainly into the "Local Institutions" and "Water Stakeholder" collective containers. Only for technical advisors (orange) and the water utilities (violet) colours coincide with the responsibility. A special mention must be made about professionals. They are hydrologist, geologists, engineers, agronomists and others who, as consultants, carry out part of the preparatory work for the plans, according to the rules adopted by each region and the decisions taken by the Basin Districts. Their role and the quality of their work are fundamental for the quality of the result, but often they are not even considered in any overview of the directives. They are often involved again as consultants in the application of measures. As technically informed citizens, they participate

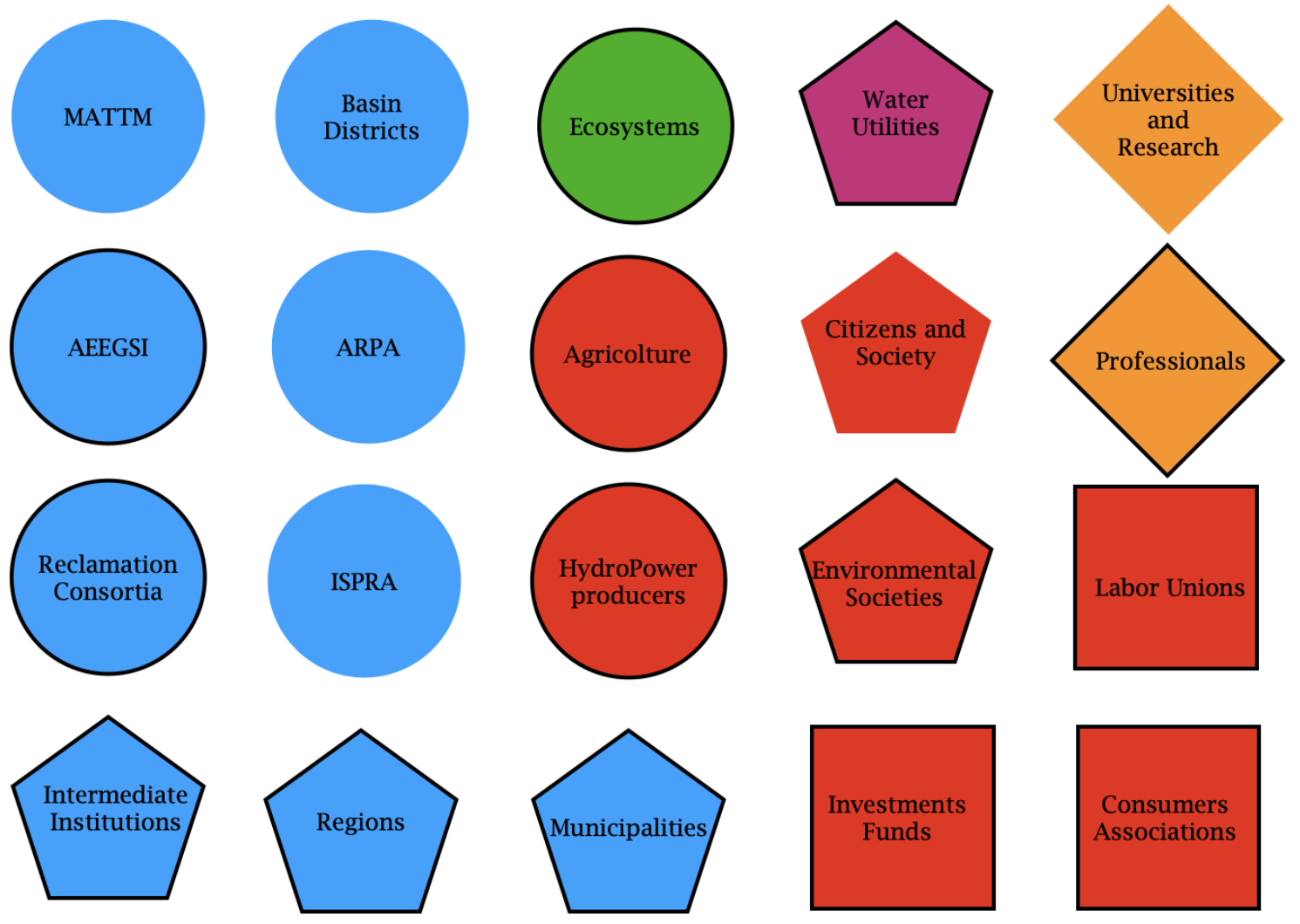

Figure 5 - Stakeholders of the WFD and FD: managers of the resource (in circles), managers of water services (in squares), managers of both (in pentagons) and providers of technical advice (in diamonds). Colours are blue for public institutions, red for interest groups or lobbies and bordered icons are those not included explicitly in Figure 3. 
in discussion forums and round tables created through the implementation of the directives opens. For all these reasons, they cannot be forgotten.

Finally, in Figure 5, we have dared to show the public interest embodied by ecosystems (green circle). They are, in principle, one of the main subjects of the WFD, though they are not thought of as stakeholders, and their interests must be defended as if they were a group of persons. Actually doing so would provide better placement of the ecosystem services they provide.

\section{3 - An overview of what has been done (How)}

The above described organization provided the 2016 deployment of second RBMPs and first FRMPs. As mentioned, the governance picture was only completed in 2015 with L. 221/2015. Therefore, the application of the directives up to 2016 was, in most cases, a collection of what was ready before and without a clear director of the process. The actual paper products of that implementation are indexed at the MATTM site ${ }^{11}$. Following the links leads to thousands of pages written from different perspectives and without a standard layout. However, in accordance with Art. 18 of the WFD and Art. 16 of the FD, the European Commission has drafted a report (European Commission 2019a) about the implementation of these Directives that provides an assessment of the related plans (the second RBMPs and the first FRMPs) of all Member States. As an annex to the report, the European Commission has provided a country-specific assessment for each plan - for Italy they are European Commission 2019b, 2019c and they provide a synthesis of the application of the Directives in Italy.

\section{1 -Implementation of the WFD in Italy: second RBMPs}

For the second cycle of the WFD, the eight Districts published their RBMPs between 17 December 2015 and 29 June 2016. According to European Commission 2019b, the first notable aspect of WFD implementation in Italy is that between the first and the second implementation cycles there has been an increase in the number of water bodies. The factors that led to this vary within the same RBDs since the analyses were carried out at the regional level (e.g. monitoring, division or unification of water bodies, more hydrogeological knowledge, etc.). The definition of significant pressures was also characterized by different approaches, with the tools used to assess point and diffuse source pressures varying between RBDs. Generally, Italy's RBMPs identified organic, chemical and nutrient pollution as having the most significant impacts on surface water bodies and groundwater.

11 The RBMPs at https://www.minambiente.it/direttive/aggiornamento-dei-piani-di-gestione-dei-baciniidrografici and the FRMPs at http://www.pcn.minambiente.it/mattm/pgra/ 
The ecological status of surface water bodies was classified for most water bodies. Also, methods to quantify the biological quality, based on the definition of the reference conditions and class boundaries, were defined and intercalibrated for all relevant biological quality elements, as specified in point 1.1 in Annex V of the WFD. At the same time, monitoring of ecological status improved with respect to the first cycle, thanks to D.M. 56/200912 and D.M. 260/2010 ${ }^{13}$, which imposed monitoring compliant with WFD requirements. This also improved confidence in the ecological status/potential classification that were found. Some gaps remain, mainly in hydromorphological and biological quality elements (for lakes, transitional, as estuaries and lagoons, and coastal waters) and in hydrological regime monitoring. For instance, the morphological conditions of coastal waters are monitored only in the Eastern Alps and Padan RBDs.

With regard to the chemical status of surface water bodies, there were improvements in all of Italy's RBMPs with respect to the first cycle. In fact, the number of surface bodies with unknown status decreased and the good chemical status was attributed to a larger proportion of water bodies. In addition, the number of monitoring sites increased, as well as the number of surface bodies monitored. However, even for the chemical status, some gaps in monitoring remain. For example, long-term trend assessment arrangements are only in place for four RBDs (Eastern Alps, North Apennines, Padan and Serchio) and the monitoring of most Priority Substances discharged, as defined in Directive 2008/105/EC ${ }^{14}$, is explicitly present in only five RBMPs.

Regarding groundwater, in the second cycle the good quantitative and chemical status was attributed to a larger number of groundwater bodies but number bodies with unknown quantitative status increased slightly overall (i.e. it decreased in the Eastern Alps, Padan and Sardinia RBDs, but increased in the North Apennines, Central Apennines and South Apennines RBDs). In all of Italy's RBMPs, the quantitative status was assessed with "a water balance method" but this was applied in differently in the various RBDs. On a positive note, to achieve national coordination in line with the European Commission's recommendations,

\footnotetext{
${ }^{12}$ Ministerial Decree 14 April 2009, n. 56 - Regolamento recante «Criteri tecnici per il monitoraggio dei corpi idrici e l'identificazione delle condizioni di riferimento per la modifica delle norme tecniche del decreto legislativo 3 aprile 2006, n. 152, recante Norme in materia ambientale, predisposto ai sensi dell'articolo 75, comma 3, del decreto legislativo medesimo»

${ }^{13}$ Ministerial Decree 8 November 2010, n. 260 - Regolamento recante i criteri tecnici per la classificazione dello stato dei corpi idrici superficiali, per la modifica delle norme tecniche del decreto legislativo 3 aprile 2006, n. 152 , recante norme in materia ambientale, predisposto ai sensi dell'articolo 75, comma 3, del medesimo decreto legislativo.

${ }^{14}$ Directive 2008/105/EC of the European Parliament and of the Council of 16 December 2008 on environmental quality standards in the field of water policy, amending and subsequently repealing Council Directives 82/176/EEC, 83/513/EEC, 84/156/EEC, 84/491/EEC, 86/280/EEC and amending Directive 2000/60/EC of the European Parliament and of the Council.
} 
in 2017 ISPRA published a national guideline (SNPA 2017). As for the chemical status of groundwater, not all substances causing risk have a threshold in all RBDs and both the threshold and the extent of exceedance of a groundwater quality standard are computed using different methods in different RDBs (Sicily's RBMP reported no method at all). In terms of monitoring, half of all groundwater bodies are not monitored for quantitative status and only have surveillance monitoring for chemical status.

As to the designation of Heavily Modified and Artificial Water Bodies, there was progress with respect to the first cycle, thanks to the introduction of a common national methodology with the D.M. 156/2013 ${ }^{15}$. However, in some RBMPs the designation is still in its preliminary phase or ongoing. In addition, since the national methodology for the definition of Good Ecological Potential was introduced later with the D.D.341/STA ${ }^{16}$ of 2016, no RBMPs have reported this information.

In accordance with Art. 4 of the WFD, all of Italy's RBMPs reported the environmental objectives for surface water bodies, in term of ecological and chemical status, and for groundwater, in terms of chemical and quantitative status; they also reported the exemptions to the achievement of the objectives. The number of exemptions, as defined under Art. 4(4) and Art. 4(5), increased with respect to the first cycle and the justifications provided changed depending on the reason and the different RBDs. For example, technical feasibility (all RBDs), natural conditions (Eastern Alps, Padan, Central Apennines and Sardinia) and disproportionate costs (Padan, North Apennines, Serchio, and Central Apennines RBDs) were the reasons given for exemptions under Art. 4(4).

To achieve the environmental objectives, all the RBMPs considered Key Types of Measures (KTMs) for all significant pressure category, for both surface water and groundwater. To 21 pre-defined KTMs (from the 25 KTMs recommended in the WFD Reporting Guidance 2016 ${ }^{17}$ ) Italy added another 16 nationally derived KTMs, for an overall mapping of 2,351 national basic measures. In addition, 824 national supplementary measures, related to 23 pre-defined KTMs and 10 nationally derived KTMs, were also mapped. These measures covered all the types of measures required by Art. 11(3) and are listed in European Commission 2019b.

\footnotetext{
${ }^{15}$ Ministerial Decree 27 November 2013, n. 156 - Regolamento recante i criteri tecnici per l'identificazione dei corpi idrici artificiali e fortemente modificati per le acque fluviali e lacustri, per la modifica delle norme tecniche del decreto legislativo 3 aprile 2006, n. 152, recante Norme in materia ambientale, predisposto ai sensi dell'articolo 75, comma 3, del medesimo decreto legislativo.

${ }^{16}$ Decree of the General Director 30 May 2016, 341/STA - classificazione del potenziale ecologico per i corpi idricifortemente modificati e artificiali fluviali e lacustri.

${ }^{17}$ Available at http://cdr.eionet.europa.eu/help/WFD/WFD 521 2016/Guidance/WFD ReportingGuidance.pdf
} 
The programme of measures for all RBDs includes those measures required to accomplish both WFD and FD objectives. For instance, the Eastern Alps RBD applied the "Natural water retention measures" KTM to flood protection, and the Padan RBD considered the interaction between green infrastructure and the FD. In addition, all the RBMPs except for the one for Sicily, reported that structural measures (e.g. flood defences) were designed or adapted to be consistent with WFD objectives.

In the second cycle, six RBDs (all but Southern Apennines and Sicily) carried out costeffectiveness analyses and most of these identified funding to guarantee coverage for the second programmes of measures implementation. This approach resulted in the identification of differences in water service ${ }^{18}$ between RBDs: for example, the Serchio RBD reported three water services, while the Eastern Alps and the Northern Apennines reported five. Among other things, D.M. 39/2015 ${ }^{19}$ introduced a methodology for the estimation of environmental and resource costs, defined "as the costs of measures required to fill the gaps to achieving the good water status objective". However, in the majority of RBMPs, this methodology was mentioned but not applied.

Finally, all the RBDs considered climate change, in some cases with specific sub-plans. The Padan, North Apennines, Sardinia and Sicily RBDs used the Common Implementation Strategy Guidance Document No. 24 (European Commission 2009) as guidance on climate change adaptation. In addition, drought management plans were reported by all RBDs, except for the Sicily and Southern Apennines RBDs.

\section{2 -Implementation of the FD in Italy: first FRMPs}

As mentioned above, according to European Commission 2019c, 47 Units of Management (UoM) were appointed as part of the implementation of the Directive in Italy. The FRMPs were prepared at different levels: some at UoM level, some at sub-UoM level, some at RBD level (which contains multiple UoMs), and in some RBDs there are FRMPs at both RBD and lower levels. In particular:

- the Eastern Alps FRMP was drafted at RBD level;

- the Central Apennine FRMP covered the whole RBD with multiple UoMs, each of which had its own FRMP;

- the FRMPs of the Northern Apennine RBD were drafted at UoM level;

\footnotetext{
18 As described in the WFD "Water services means all services which provide, for households, public institutions or any economic activity: (i) abstraction, impoundment, storage, treatment and distribution of surface water or groundwater, (ii) waste-water collection and treatment facilities which subsequently discharge into surface water".

${ }^{19}$ Ministerial Decree 24 February 2015, n. 39 - Regolamento recante i criteri per la definizione dei costi ambientali e della risorsa per i vari settori d'impiego dell'acqua.
} 
- the Southern Apennines RBD prepared an overall FRMP at RBD level and regional level plans;

- where the UoM corresponds to the entire RBD (i.e. Sicily, Sardinia, Padan and Serchio), only one FRMP was drafted.

All of Italy's FRMPs, except for Sicily's, was adopted in December 2015 and approved by RBD authorities in March 2016 and by the National Council of Ministers in February 2017. Sicily's FRMP was characterized by delayed administrative steps. The plan was adopted by RBD Committee in February 2016, approved with D.G.R. 274/201820 in July 2018, and then also by the National Council of Ministers in September 2019. Please, note, after the deadline for the application.

As permitted by Art. 13 of the Flood Directive, none of the UoMs undertook a Preliminary Flood Risk Assessment (PFRA) or identified Areas of Potential Significant Flood Risk (APSFRs). Indeed, according to the D.Lgs. 152/2006 Art. 67, the Basin Authorities had prepared a Hydrogeological Status Plan (Piano di Assetto Idrogeologico, PAI), which contains the flood hazard and risk maps and the implementation rules to safeguard the territory from hydrogeological risk, on the same terms as the FD. All the FRMPs used PAIs as a starting point for the Flood Hazard and Risk Maps (FHRMs), which were updated with further data and studies. There are some differences in the drafting between FHRMs of different UoMs. In terms of hazard, the main differences concerned:

- the methodologies used to map flood hazards (e.g. some FHRMs were computed by hydraulic simulations, while others are based on historical data);

- the hazard elements shown on the maps (e.g. some FHRMs did not report the flow depth and the flow velocity);

- the flood sources considered. Primarily, the FRMPs considered river flooding. Some UoMs also considered pluvial flooding (e.g. Sardinia) and/or the coastal flooding (e.g. Tuscany). Other flooding sources, such as groundwater, artificial water-bearing infrastructure, and sewerage systems, were generally not considered. An exception is the FRMP of the interregional Tronto Basin, where dam breach of the Campotosto Lake was considered as a potential hazard.

Almost all the UoMs divided the FRM objectives into four risk categories: reduction of risk (or of adverse consequences) to human health, cultural heritage, environment and economic activities. To achieve the FRM objectives, the measures are divided into four types: prevention, protection, preparedness, and recovery and review. As part of the implementation, the UoMs proposed a total of 10,067 aggregated measures but, since some

\footnotetext{
${ }^{20}$ Decision of the Regional Government 25 July 208, n.274 - Piano di gestione del rischio di alluvioni Attuazione della Direttiva 2007/60/CE relativa alla valutazione e alla gestione dei rischi di alluvioni Aggiornamento.
} 
measures were assigned to more than one measure type, the total number of individual measures was 8,348 . The degree of detail with which the measures were described varied greatly between FRMPs. The cost of the measures (non-mandatory information) was reported by some UoMs (e.g. the Puglia Region and the interregional Ofanto basin, the Sicily Region, and the Serchio basin) and the related funding was reported as derived mainly from the use of public budget at national, regional and local level. The RBD/UoM, sub-basin or APSFR are the principal level locations ${ }^{21}$ where the measures are to be reached. However, some FRMPSs (e.g. the Puglia Region and the interregional Ofanto basin) grouped the measures in terms of sub-basin without explicitly identifying their specific location. In addition, 10 UoMs belonging to the Eastern Alps district provided a schedule of measures, while 37 UoMs did not report any information on this aspect.

The prioritization of measures was also done with different approaches by different RBDs. For example, the Central Apennine District followed the multicriteria approach proposed by ISPRA (ISPRA 2015). According to this approach, the measures are divided into four categories of objectives (reduction of risk to human health, cultural heritage, environment, and economic activities) and then into another twelve specific sub-objectives. Other RBDs chose different categorization classes.

In terms of consistency and coordination between the WFD and the FD, the FRMPs differ on the level of information provided and not all of them make express reference to the objectives reported in Art. 4 of the WFD. In general, the coordination between the two directives relates to the shared data (e.g. hydrographic network) and some FRMPs provided measures aimed at achieving objectives for both the FRMP and the RBMP. For example, the Padan FRMP established 159 so-called win-win measures that contributed to WFD and FD compliance. On the other hand, no explicit mention of the WFD objectives was made in the FRMP for the Sangro Interregional Basin and Abruzzo Region.

To account for Italy's Climate Change Adaptation Strategy (Strategia Nazionale di Adattamento ai Cambiamenti Climatici - SNAC) (MATTM 2015), which was approved in June 2015 with the D.D. 86/2015²2 (the related Climate Change Adaptation Plan has not yet been approved), all UoMs stated that climate change impact will be analysed during the second implementation cycle of the FD. However, some phenomena that are probably closely related to climate change were already considered in some FRMPs. For example, some UoMs of the Northern Apennines RBD developed a method to analyse, map and

\footnotetext{
${ }^{21}$ Other possible levels are: international, national, water body, municipal or local.

${ }^{22}$ Directorial Decree 16 June 2015, n. 86 - Approvazione del documento "Strategia Nazionale di Adattamento ai Cambiamenti Climatici".
} 
prevent flash floods. In addition, Sardinia's FRMP included an assessment of the SNAC in order to evaluate the consistency of the objectives.

\section{4 - Critical analysis and discussion}

Since the publication of the Management Plans for the implementation of the Directives, various comments and suggestions have been made but they have not found a systematic collector. However, as mentioned earlier, in February 2019 the European Commission issued a report about the Directives that included an assessment of the related implementation plans of all Member States (European Commission 2019a).

In Italy, what finally made the governance chain described above functional was L. 221/2015. Even though Basins Districts were formally instituted by D.Lgs. 152/2006, it is probable that the absence of legislation similar to L. 221/2015 caused the more evident weaknesses of the Italian application of the directives, as noted by European Commission 2019a. That is to say, the lack of harmonization between regional approaches and the lack of definition of relevant pressures in the RBMPs.

The second implementation cycle of the WFD and the first of the FD fell to Basin Districts without clear and well-defined responsibilities. Therefore, part of the work was performed according to the older Italian water governance, which contemplated a larger number of districts, called "Basin Authorities". This approach especially affected the implementation of the FD application, which was divided among the UoMs mentioned in sections 2 and 3. For the RBMPs, a very different line of governance was evident, with the Regions having great influence on the determination and acquisition of quality indicators.

The starting point for the FRMPs were the maps prepared for the PAI, which were planned around the UoM and accomplished by using mostly historical data and obsolete methods. The process of merging the old with the new had no clear direction and, more importantly, had no clear allocation of funds for the work to be done. This was caused, in part, by the RBDs not having financial independence; they depend on the MATTM that, in turn, did not have a full legitimacy until D.Lgs. 152/2006 was ratified. More information may be given on funding sources for measures in the second and third implementation cycles of the FD and WFD respectively, as required by European Commission 2019a.

In this uncertainty, all subjects involved were pressed to rush to a conclusion without the necessary overall coordination. On the side of harmonization, it is easy to see that management plans, though built on essentially the same scientific premises and often with similar tools, can differ widely. For instance, regarding water services and uses, although defined by D.M. 39/2015 on a national level, each RBMP identified the relevant ones based on pressures and impact assessments. 
RBMPs and FRMPs also differ in their organization of subjects, methods and contents. Even within the same district, when larger than one UoM, one can recognize different imprints and this is due to the trivial fact that the final drafts followed a different development, with different chapters and different sections.

Currently, there is not an Italian website that gathers all the contributions of the districts together in a reasoned manner. There is one site managed by MATTM ${ }^{13}$ but, so far, it is just a collector of links. Wanting to answer to the criticism about harmonization, in the next cycle of application, the coordination of work should start from a common protocol that starts with data collection, storage and availability, continues with tools and models used, and concludes with indications for report dissemination.

However, there are criticisms that can be levelled directly to the EU. Not much thought was given in advance to streamlining some of the thousands of aspects included in the directives, and the geographic scales of application were left too generic. Member States have had to find their own way and objectives, seldom in coordination with anybody.

One of the weaknesses in Italy is that sometimes indicators are produced in the chains of decisions that are not sufficiently clear, where technical people underestimate the conflicts they can cause among stakeholders and, while not responsible for the costs they can generate for society, in practice they are asked to take political choices with far-reaching implications which are, in some cases, not made explicit enough to the communities involved. This is a defect of the overall architecture of the governance system and, if not resolved, will cause the planned measures to fail or be opposed during or even after their deployment. This may well be common to other states too since in recent years it has become a growing topic of interest in the scientific community. Subjects like socio-hydrology and socio-hydraulics found a new impulse to promote ways to eliminate these defective attitudes. Among the experiences, the European project LIFE FRANCA (Flood Risk ANticipation and Communication in the Alps - www.lifefranca.eu) identified some interesting new way to sharing information, and many other projects are ongoing, such as the ERC project HydroSocialExtremes (www.hydrosocialextremes.org), for example.

In its reports and assessment (European Commission 2019a, 2019b, 2019c), the EU seems to be focused on costs in a strictly budgetary sense (e.g., "assure the correct application of Art. 9 of the directive on costs recovery, including environmental and resources costs" in European Commission 2019a), but the cost can be categorized as social and economical in a broader sense. This is manifest when indicators favour one or another stakeholder group without a proper discussion of the related issues.

The other big issue is data quality and availability. Data are provided by ARPA and APPA by means monitoring networks that are sometimes well equipped but more 
frequently poor, especially regarding the quality of waters and discharges of streams. For hydrometeorological stations, quality seems assured but other data are retrieved in a variety of situations that make them of uncertain reliability. While the meteorological stations network is decent, if not optimal, the gauging stations are still scarce. Rating curves to estimate discharges from stage measurements at a specific gauging station are often not released to users and obsolete while no reliable results can be obtained without them.

In European Commission 2019a, there are at least two main observations made to Italy:

- to provide the relevant information about discharges and measurements and, in the specific, clarify how the monitoring objectives can be achieved (i.e. in the management plans, the priority given to measurements must be systematically indicated);

- to tackle the urban wastewater issues and implement enough measures to achieve what the WFD asks (as well as the wastewater directive in all basins).

There is no doubt that these observations must be answered in 2021. Many ARPAs release data according to an open source protocol, but others do not disclose them at all, despite a clear and recent law about open data (D. Lgs. 102/2015) ${ }^{23}$, which seems to be mostly ignored or passively resisted. Lack of data slows any process down from the very beginning and makes the results, as required by the directives, unreliable. Also, it is an obstacle to the growth of those businesses that base their activities on the use of environmental data and hinders fair competition between enterprises. Obviously, this topic is particularly important when dealing with water use and the business of the water utilities.

There are also other technical deficiencies, such as the INSPIRE protocols, introduced with the 2007/2/EC 24 and related to metadata, interoperability of spatial data sets and services, network services and data sharing. They are rarely adopted and data deployment remains fragmented into as many directions as there are data providers.

In its short life, Italia Sicura tried to overcome these limitations and offer some nationwide data. The effort was welcome, but it was not the coordination action required, which should have involved MATTM, ISPRA and ARPA together to generate unique protocols and delivery options. A typical example is the intake of water for hydropower plants (but could just as likely be for agriculture or other uses). Companies consider these data "sensitive information", their ownership provides advantage to their business and, as such, they should not be shared with anyone. The limits of this argument become evident when we consider that waters are public and, therefore, any limitation to public access to their

\footnotetext{
${ }^{23}$ Legislative Decree 18 may 2015, n. 102 - Attuazione della direttiva 2013/37/UE che modifica la direttiva 2003/98/CE, relativa al riutilizzo dell'informazione del settore pubblico.

${ }^{24}$ Directive 2007/2/EC of the European Parliament and of the Council of 14 March 2007 establishing an Infrastructure for Spatial Information in the European Community (INSPIRE).
} 
status is justifiable only if there is a collective advantage to be had. EU commissioners write in European Commission 2019a that it is necessary to measure all water intakes because this is the condition necessary to take decisions in critical situations like draughts and others. There cannot be a full application of the directives if there is not an appropriate policy making the necessary data open and easily accessible, taking for granted that they are of good quality, of course.

Finally, European Commission 2019a recalls a few actions to be taken with respect to future FRMPs, which we note here without further comment:

- develop a clear connection between objectives and measures;

- provide a better explanation of how monitoring has to be done (or has been done);

- extend cost-benefit analyses to the selection and classification of action priorities whenever possible;

- coordinate the FD actions with the National Climate Change Adaptation Strategy.

A discussion on the methods used to assess the state of the water environment is not present in an analysis of the application of the directive such as this one - it would grow too technical, long and non-effective, but at some point, it will be important to do so. At this level, it is probably more important to dissect at least a little the process that brings to the application of science in the directives.

\section{5 - The science behind the scenes}

In the WFD and FD, knowledge of how water moves in the environment, interacting with sediments and the landscape, is the basis of any action and farsighted policy and, therefore, any planning. In stating this, we do not want to affirm the primacy of science over politics but certainly we state that science, for its systematic nature and reproducibility, can help politics much more than providing occasional observations or opinions. In fact, if the final practical outcomes of a practitioner's work are indicators or maps of indicators, which in turn affect measures that affect the life and well-being of people and society, then there is the necessity of a solid foundation: a science that has to be developed and maintained.

Sciences like hydrology, hydraulics, geology and ecology do not contribute merely by providing tools for a purpose. They first provide the context of the discussions and build the proper perception, the consciousness, of the role played by nature in creating our wellbeing, now and in the long term. They provide the elaboration of the idea itself of Nature, which actually promoted the directives being discussed.

There are aspects of the general discussion that regard the dichotomy between Nature and Safety. The WFD, once stripped down to norms and maps, proposes a vision of Nature that is implicitly assumed as good. The FD, on the other hand, privileges Safety, which is 
also good but often to the detriment of Nature. Historically, the two cultures (of Nature and Safety) tended to clash (because in the short-term Nature can be unsafe). For the future, we need a new synthesis, which reclaim a deeper interplay between science, society and politics, because the apparently academic discussion has, in reality, several implications on the decision-making. It is also apparent that if citizens are not able to grasp this level of discussion, they miss something they need to be fully aware of their own lives.

Obviously, there is also the practical layer, where we focus our attention more often, that comprises the tools required for implementation of the directives. This was the rationale behind D.P.C.M. 38/2013, which established an organized channel for interaction between administrations and the research producing the tools. The flow of information flow from research and practitioners continues but, unfortunately, it is largely disorganized and underfinanced. So far, it has worked thanks to personal or territorial relationships, with all of the fragmentation that this implies. The Academy actually felt that this approach was limitative and, as a consequence, various initiatives for discussion and coordination started, such as, for instance, the GRAL group (Gruppo Alluvioni, Flood Group) or the group of Universities forming in these days around the AIPo to fill the existing gaps in knowledge transmission.

If the implementation cycles of the directives are not used to rethink the tools, and the science behind them, it will be a missed opportunity that will not be recovered by other efforts, since scientific projects financed by the EU have mostly other objectives. And there are many aspects to rethink, functionally to the environment that we address locally and globally, i.e. at multiple scales. For the most part, indicators were designed for large-scale problems (such as coasts or large river conservation and flooding). They are not necessarily indicative of the quality of small or mountain catchments as they are focused on water and not on the accompanying sediment, for example, and therefore would be inadequate for their scope of showing the truth about the water status.

Being even more specific, the hydraulic and hydrological tools used to produce management plans are at best ten years behind the current state of the art. We do not have space here for a detailed review of the tools currently used by institutions, but they have some common characteristics. Hydraulic analysis is mostly done with a few commercial tools developed by Dutch or UK companies based on twenty-five years old science. They do not deal properly with sediments and with the interaction between groundwater and surface water. Hydrology tools are, on average, more recent but mostly oriented to flood forecasting. Those intended to support water management are poorer, with attention to snow production and its effects being highly parameterized (meaning simplified), 
evapotranspiration poorly represented, information from remote sensing resources seldom included, and soil moisture simply neglected.

This is a worldwide situation, but it is easy to see that much can be done to improve it. Regional institutions put great effort into building closed systems that are mostly incompatible and cannot be compared easily in their performances, limiting the ability to learn from each other. The same situation presents itself when we look at the work of single workers. They use mostly incompatible tools and concepts, which makes it difficult to know if they did it right. Because the chain of tools used is not replicable by third parties, if a judgement is needed, it can be made only on the overall process and the declared features. Obviously, this is not good. With both open source and commercial software, simulation replicability and third-party reviews should be made mandatory in future protocols. Basic platforms, models containers, and webgis presentations of the results should present open specifications to allow interoperability between different solutions.

\section{6 - Conclusions and hopes}

From the analysis and discussion presented, it should be evident that efforts in applying the directives was huge but certainly in need of a "refactoring". This should concern coordination between territorial Institutions to provide common indicators, common procedures, and common guidelines for the drafting of documents with the same layout and format.

Coordination should start with common protocols for data provision according to open access schemes. MATTM and ISPRA, in line with their mission, should take the lead in recognizing discrepancies between plans and persuading the RBDs to effect homogeneous analyses. The problem of data is of fundamental importance for science also, despite being in the background, and the matter was discussed previously.

RBMPs should consider droughts more explicitly as, under the pressure of climate change, they will become the most relevant issue in many parts of the country, especially the South where drier climate is already hitting.

From a technical standpoint, a set of problems requiring debate regards the adequate choice of quality indicator and of sound methods for mapping hazards and pressures. Once agreed, these should be adopted as a basis for all regions and RBDs. However, to obtain this, someone has to start the cumbersome but necessary comparative analysis of what was done in past implementation cycles, delving into the macro weaknesses we are only highlighting here, and going into the details of the process - after all, the rationale of the final decision depends on them. 
There is already a continuous transfer of expertise and knowledge from where science is produced to where it is deployed, due to the turnover of officials and new positions in public institutions. However, a systematic coordination for knowledge transfer would produce far better results than the good will of individuals. This coordination does not need to be headed by researchers. Indeed, it may prove more effective if it came through a direct action of MATTM and ISPRA towards the research community, as represented by its many groups of interest and disciplinary associations. Obviously, such a coordination effort would require its own funding and organization.

Organs like the Alpine Convention ${ }^{25}$ had a pioneering importance in offering a place for comparison of approaches to WFD and FD in the context of the Alpine regions. A wider context of comparison could be offered at the level of the entire EU, maybe through comparison with societies like the European Geoscience Union (EGU), which are certainly interested in the process and gather thousands of researchers. It is paramount that good practices of the application of the directives at the European level be brought to the attention of everyone before the new application cycle begins.

After almost five years since the 2016 implementation, some statistics should be available to check what is the state of implementation of the planned measures: how they were funded in the end and if they were effective after all. It would also be the right time to collect bottom-up experiences to inform reform of directive practices, which could them even more useful to the communities.

\section{List of acronyms}

\begin{tabular}{|c|c|}
\hline AEEGSI & $\begin{array}{l}\text { Electricity, Gas and Water System Authority - } \\
\text { Autorità per l'Energia Elettrica il Gas e il Sistema Idrico }\end{array}$ \\
\hline AIPO & $\begin{array}{l}\text { Interregional Agency for the Po River - } \\
\text { Agenzia interregionale per il fiume Po }\end{array}$ \\
\hline APSFR & Areas of Potential Significant Flood Risk \\
\hline ARPA/APPA & $\begin{array}{l}\text { Regional/Provincial Environmental Protection Agency - } \\
\text { Agenzia Regionale/Provinciale per la Protezione dell'Ambiente }\end{array}$ \\
\hline $\mathrm{CC}$ & Competence Centres \\
\hline DPC & $\begin{array}{l}\text { Civil Protection Department - } \\
\text { Dipartimento di Protezione Civile }\end{array}$ \\
\hline EGU & European Geosciences Union \\
\hline
\end{tabular}

\footnotetext{
${ }^{25}$ https://www.alpconv.org/
} 
FHRM Flood Hazard and Risk Map

FRMP Flood Risk Management Plan

GRAL Gruppo Alluvioni -

Flood Group

ISPRA National Institute for Environmental Protection and Research -

Istituto Superiore per la Protezione e la Ricerca Ambientale

KTM Key Types of Measures

MATTM Ministry of Environment -

Ministero dell'Ambiente e della Tutela del Territorio e del Mare

PAI Hydrogeological Status Plan -

Piano di Assetto Idrogeologio

PFRA Preliminary Flood Risk Assessment

PoM Program of Measure

RBD River Basin District

RBMP River Basin Management Plan

SNAC Climate Change Adaptation Strategy -

Strategia Nazionale di Adattamento ai Cambiamenti Climatici

SNPA National System for the Environment protection -

Sistema nazionale per la protezione dell' Ambiente

UnoMit of Management

WFD Water Framework Directive (2000/60/EC)

\section{Bibliography}

Coen, L. (2006). The current situation of international functions of Italian regions. Matriosca AdriaAlpe-Pannonia Project WP.

European Commission (2003a). Common implementation strategy for the Water Framework Directive (2000/60/EC). Guidance Document No. 3. Analysis of Pressures and Impacts. (Available at https://circabc.europa.eu/sd/a/7e01a7e0-9ccb-4f3d-8cec-aeef1335c2f7/Guidance\%20No\%203\%20 \%20pressures\%20and\%20impacts\%20-\%20IMPRESS\%20(WG\%202.1).pdf)

European Commission (2003b). Common implementation strategy for the Water Framework Directive (2000/60/EC). Guidance Document No. 7. Monitoring under the Water Framework Directive. (Available at https://circabc.europa.eu/sd/a/63f7715f-0f45-4955-b7cb-58ca305e42a8/ Guidance\%20No\%207\%20-\%20Monitoring\%20(WG\%202.7).pdf) 
European Commission (2003c). Common implementation strategy for the Water Framework Directive (2000/60/EC). Guidance Document No. 11. Planning Processes. (Available at https://circabc.europa.eu/sd/a/4de11d70-5ce1-48f7-994d-65017a862218/Guidance\%20No\%2011\% 20-\%20Planning\%20Process\%20(WG\%202.9).pdf)

European Commission (2009). Common implementation strategy for the Water Framework Directive (2000/60/EC). Guidance Document No. 24, River Basin Management in a changing climate. (Available at https://circabc.europa.eu/sd/a/a88369ef-df4d-43b1-8c8c-306ac7c2d6e1/Guidance \%20document $\% 20$ n $\% 2024 \% 20-\% 20$ River\%20Basin\%20Management $\% 20 \mathrm{in} \% 20 \mathrm{a} \% 20$ Changing\%20 Climate FINAL.pdf)

European Commission (2014). Links between the Floods Directive (FD 2007/60/EC) and the Water Framework Directive (WFD 2000/60/CE). Technical Report - 2014 - 078. (Available at https://op.europa.eu/it/publication-detail/-/publication/5e8ddc30-ed98-47f3-872c-de78851c721f)

European Commission (2016). Introduction to the New EU Water Framework Directive. (Available at http://ec.europa.eu/environment/water/water-framework/info/intro en.htm).

European Commission (2019a). Report from the Commission to the European Parliament and the Council on the implementation of the Water Framework Directive (2000/60/EC) and the Floods Directive (2007/60/EC). Second River Basin Management Plans. First Flood Risk Management Plans. (Available at https://eur-lex.europa.eu/resource.html?uri=cellar:bee2c9d9-39d2-11e9-8d0401aa75ed71a1.0005.02/DOC 1\&format=PDF

Annex available at https://eur-lex.europa.eu/resource.html?uri=cellar:bee2c9d9-39d2-11e9-8d0401aa75ed71a1.0005.02/DOC 2\&format=PDF)

European Commission (2019b). Commission Staff Working Document, Second River Basin Management Plans - Member State: Italy Accompanying the Document "Report from the Commission to the European Parliament and the Council on the implementation of the Water Framework Directive (2000/60/EC) and the Floods Directive (2007/60/EC). Second River Basin Management Plans. First Flood Risk Management Plans". (Available at https:/eurlex.europa.eu/legal-content/EN/TXT/PDF/?uri=SWD:2019:51:FIN\&qid=1551205988853\&from=EN)

European Commission (2019c). Commission Staff Working Document, First Flood Risk Management Plans - Member State: Italy Accompanying the Document "Report from the Commission to the European Parliament and the Council on the implementation of the Water Framework Directive (2000/60/EC) and the Floods Directive (2007/60/EC). Second River Basin Management Plans. First Flood Risk Management Plans". (Available at https:/eurlex.europa.eu/legal-content/EN/TXT/PDF/?uri=SWD:2019:81:FIN\&qid=1551205988853\&from=EN)

ISPRA. “Inquadramento Storico Del Monitoraggio Idro-Meteografico e Delle Relative Competenze.” Istituto Superiore per La Protezione e La Ricerca Ambientale, www.isprambiente.gov.it/it/progetti/acque-interne-e-marino-costiere-1/progettoannali/inquadramento-storico-del-monitoraggio-idro-meteografico-e-delle-relative-competenze

ISPRA (2015). NOTE sulla compilazione del Database Access conforme agli SCHEMA per il reporting della Dir. 2007/60/CE art. 7: Piani di Gestione del Rischio Alluvioni.(Available at http://www.isprambiente.gov.it/pre meteo/file/NOTE db access FMRP agosto2015.pdf) 
MATTM (2015). Strategia Nazionale di Adattamento ai Cambiamenti Climatici. (Available at: https://www.minambiente.it/sites/default/files/archivio/allegati/clima/documento SNAC.pdf)

Sabel, C. F., \& Zeitlin, J. (2012). Experimentalist governance. The Oxford handbook of governance, 1, 2-4.

SNPA (2017). Linee Guida SNPA n.3/2017 Criteri tecnici per l'analisi dello stato quantitativo e il monitoraggio dei corpi idrici sotterranei. (Available at https://www.snpambiente.it/wpcontent/uploads/2018/12/linee guida snpa 3 2017.pdf)

Tsakiris, G., Nalbantis, I., \& Pistrika, A. (2009). Critical technical issues on the EU flood directive. European Water, 25(26), 39-51.

Voulvoulis, N., Arpon, K. D., \& Giakoumis, T. (2017). The EU Water Framework Directive: From great expectations to problems with implementation. Science of the Total Environment, 575, 358-366. 